\title{
Chrysomya bezziana (Diptera: Calliphoridae) infestation: case report of three dogs in Malaysia treated with spinosad/milbemycin
}

\begin{abstract}
Background :Infestation of wounds with the larvae of Callophorid flies is relatively common in countries where these parasites are found. The most common species associated with infections in Southeast Asia is Chrysomya bezziana (Ch. bezziana), the Old World screw worm. Treatment consists of either subcutaneous injection of ivermectin or oral administration of nitenpyram combined with aggressive tissue debridement under general anaesthesia. Objectives: To describe the treatment of cutaneous myiasis in three dogs caused by the larvae of $\mathrm{Ch}$. bezziana in Malaysia and their treatment with spinosad plus milbemycin. Results: In all dogs, a single oral dose of spinosad plus milbemycin at the recommended dosage of $31-62 \mathrm{mg} / \mathrm{kg}$ and $0.5-1.0 \mathrm{mg} / \mathrm{kg}$, respectively, was able to kill all larvae within $8 \mathrm{~h}$. Most dead larvae fell off the host and those remaining on the host were dead and easily removed with simple saline flushing and gentle debridement. Neither general anaesthesia nor aggressive mechanical debridement were needed in any patient. Conclusiona and Clinical Importance: Oral spinosad plus milbemycin is a safe, licensed and effective treatment at the recommended dose for the rapid elimination of $\mathrm{Ch}$. bezziana myiasis, with no need for sedation or anaesthesia.
\end{abstract}

